\title{
EVALUASI PENERAPAN SISTEM HARMONISASI GLOBAL DI PT PETROKIMIA GRESIK PABRIK 1 UNIT UREA
}

\author{
EVALUATION OF GLOBALLY HARMONIZED SYSTEM IN PT \\ PETROKIMIA GRESIK FACTORY 1 UNIT UREA
}

\author{
M. Isa Rosyidi Asror, Erwin Dyah Nawawiwetu \\ Departemen Keselamatan dan Kesehatan Kerja \\ Fakultas Kesehatan Masyarakat, Universitas Airlangga \\ E-mail: isarosyidiasror@gmail.com
}

\begin{abstract}
The presence of Globally Harmonized System (GHS) in the world can not be separated from the element of risk and danger of the chemicals which are used both for humans and for the environment. PT. Petrokimia Gresik is one of companies which use a wide various of hazardous chemical elements. In the process of production and the products themselves, as found in Production Process Urea Unit. PT Petrokimia Gresik start to implement GHS in 2009 based on the regulations of the Minister of Industry No. 87/M-IND/PER/9/2009 about Globally Harmonized System of Classification and Labels On Chemicals. This study aimed to Evaluate of the implementation of the GHS as an illustration of condition of GHS application on PT. Petrokimia Gresik factory 1 unit urea. This research is descriptive study. Subjects in this study is a variety of work related to the implementation of the GHS in the urea unit and the object of this research is the implementation of the GHS. This study variables include the application of GHS such as dangers, and SDS / LDK. The results of the study showed that the GHS of PT Petrokimia Gresik had been adequately implemented (66\%), because it only fulfills 2 variables from 3 variables tested.
\end{abstract}

Keywords: evaluate, globally harmonized system, illustration

\begin{abstract}
ABSTRAK
Keberadaan Globally Harmonized System (GHS) di dunia tidak terlepas dari adanya unsur risiko dan bahaya dari bahan kimia yang digunakan baik terhadap manusia maupun bagi lingkungan sekitarnya. PT Petrokimia Gresik merupakan perusahaan yang dalam proses dan hasil produksinya menggunakan berbagai macam bahan kimia berbahaya, salah satunya adalah proses produksi dalam unit Urea. PT Petrokimia Gresik menerapkan GHS pada tahun 2009 sesuai dengan keluarnya Peraturan Menteri Perindustrian Nomor 87/M-IND/PER/9/2009 tentang Sistem Harmonisasi Global Klasifikasi dan Label Pada Bahan Kimia. Evaluasi penerapan GHS sebagai gambaran kondisi penerapan GHS pada unit urea PT Petrokimia Gresik merupakan tujuan umum dari penelitian ini. Penelitian ini merupakan penelitian yang bersifat deskriptif. Subyek pada penelitian ini merupakan berbagai fungsi pekerja yang berhubungan dengan penerapan GHS pada unit urea dan Obyek penelitian ini merupakan penerapan GHS. Variabel penelitian ini antara lain penerapan GHS yang didalamnya terdapat klasifikasi bahaya, SDS/LDK, serta pelabelan. Hasil penelitian menunjukkan bahwa PT Petrokimia Gresik dalam penerapan GHS termasuk dalam kategori cukup (66\%), karena dari ketiga variabel pada penerapan GHS PT Petrokimia Gresik hanya memenuhi dua variabel.
\end{abstract}

Kata kunci: evaluasi, gambaran, globally harmonized system

\section{PENDAHULUAN}

Keberadaan Globally Harmonized System (GHS) di dunia tidak terlepas dari adanya unsur risiko dan bahaya dari bahan kimia yang digunakan baik terhadap manusia maupun bagi lingkungan sekitarnya. Menurut Lesmana (2007), menyatakan bahwa, di dunia terdapat jutaan jenis bahan kimia dan selalu bertambah setiap harinya dengan banyaknya jumlah bahan kimia dan jenis bahan kimia yang beredar di dunia saat ini tentu memiliki risiko bahaya yang memerlukan sikap khusus atau perlakuan khusus terhadap bahan kimia tersebut 
oleh penggunanya atau user. Banyaknya jenis bahan kimia yang juga memiliki jenis dan sifat bahaya yang berbeda-beda telah membuat dunia secara internasional dan regional memandatkan untuk selalu menyediakan lembaran Safety Data Sheets (SDS) atau Lembar Data Keselamatan (LDK) dan label sebelum bahan kimia diperjualbelikan, hal ini sudah disepakati pada pertemuan di Jepang, Rio De Jeneiro, dan Jenewa menyepakati bahwa setiap negara akan mengimplementasikan GHS dan hal tersebut menjadi esensial sifatnya karena GHS adalah sumber informasi yang menjadi bahan untuk komunikasi bahaya baik oleh perusahaan atau oleh konsumen/ end user yang akan mempergunakan bahan tersebut.

Menurut Lesmana (2007), Informasi yang disediakan oleh SDS atau LDK dan label akan digunakan untuk mengembangkan perlindungan yang sesuai bagi pekerja atau konsumen dan tindakan yang diperlukan untuk melindungi lingkungan hidup. GHS membentuk satu sistem global dalam hal komunikasi bahaya yaitu klasifikasi bahaya, SDS atau LDK dan label atau penandaanya. GHS berisikan informasi penting dari unsur senyawaan atau campuran bahan kimia yang digunakan dan hal tersebut diharapkan kepada para negara yang berada dalam organisasi United Nation pada tahun 2013 untuk melakukan perubahan dan adopsi sistem GHS di seluruh dunia diharapkan dapat diimplementasikan secara menyeluruh pada tahun 2008 oleh seluruh negara di dunia, sementara amandemen perubahan peraturan lokal di masing-masing negara diharapkan akan selesai pada tahun 2006.

Survey of Asia-Pacific Countries regrading GHS Implementation mengemukakan bahwa Indonesia merupakan salah satu anggota APEC ditunjuk menjadi salah satu Pilot Country Project untuk pelaksanaan GHS di Asia Pasifik khususnya tingkat ASEAN. Keberadaan GHS di Indonesia tentunya akan membawa berbagai keuntungan antara lain karena dengan adopsi sistem GHS, adalah kejelasan dalam hal informasi bahan kimia, mudah untuk diterapkan, terdapat informasi tentang bahan kimia yang konsisten. Format SDS dan labelling akan diseragamkan di Indonesia, yaitu menggunakan format GHS yang terdiri dari 16 section/bagian menjadi SDS/LDK dan label yang berisikan 6 point isi pada label. GHS juga dapat mencegah terjadinya Penyakit Akibat Kerja (PAK) terhadap pekerja serta dapat juga mencegah terjadinya kecelakaan kerja.

Menurut Harjanto (2011), banyak sekali aspek keselamatan yang perlu diperhatikan untuk mencegah terjadinya kecelakaan. Aspek lingkungan dan manusia seperti kesejahteraan, keselamatan, dan kesehatan pekerja yang semestinya merupakan hal yang sangat penting sering kali diabaikan (Damanik, 2015). Aspek lingkungan dan manusia merupakan hal yang penting untuk melakukan pencegahan agar tidak menurunkan kinerja dari perusahaan dalam melakukan produksi.

Menurut Mansyur (2007), manajemen risiko kesehatan di tempat kerja mempunyai tujuan meminimalkan kerugian akibat kecelakaan dan sakit, meningkatkan kesempatan/peluang untuk meningkatkan produksi melalui suasana kerja yang aman, sehat, dan nyaman, memotong mata rantai kejadian kerugian akibat kegagalan produksi yang disebabkan kecelakaan dan sakit, serta pencegahan kerugian akibat kecelakaan dan kesehatan kerja. Pencegahan terhadap kecelakaan kerja, dapat melakukan beberapa hierarki pengendalian yaitu pengendalian eliminasi, substitusi, rekayasa teknik, administrasi, dan alat pelindung diri (APD). Pelaksanaan program hierarki pengendalian harus mempertimbangkan sumber daya yang ditargetkan, uang yang dikeluarkan, efisiensi dan efektivitas pengendalian tersebut juga sangat penting untuk diperhatikan. Salah satu pengendalian yang dapat menangani bahaya yang ditimbulkan bahan kimia adalah pengendalian administrasi.

Pengendalian administrasi memiliki beberapa macam item dalam penerapannya, salah satunya adalah tentang komunikasi bahan kimia. GHS dapat menjadi suatu alat dalam melakukan pencegahan kecelakaan kerja terhadap bahan kimia karena pada GHS berfungsi untuk klasifikasi bahaya, SDS dan label atau penandaannya.

Berdasarkan peristiwa tersebut, suatu pabrik harus memiliki cara pengendalian dan melakukan pencegahan kecelakaan dengan tepat. Globally Harmonized System (GHS) atau Sistem Harmonisasi Global dapat menjadi salah satu solusi tepat untuk pengendalian dan pencegahan kecelakaan bahaya karena didalam penerapan sistem harmonisasi global yang telah diatur dalam Peraturan Menteri Perindustrian Republik Indonesia Nomor 23/MIND/PER/4/2013 tentang Perubahan Atas Peraturan Menteri Perindustrian No. 87/M-IND/PER/9/2009 tentang Sistem Harmonisasi Global Klasifikasi dan Label pada Bahan Kimia dan Peraturan Direktur Jendral Basis Industri Manufaktur Nomor 04/BIM/ PER/1/2014 tentang Petunjuk Teknis dan Petunjuk Pengawasan Pelaksanaan Sistem Harmonisasi Global Klasifikasi dan Label pada Bahan Kimia terdapat 
bagaimana cara menyikapi bahan kimia yang berbahaya untuk melindungi kesehatan, keamanan dan keselamatan masyarakat dan lingkungan dari risiko bahan kimia serta perbedaan klasifikasi dan pelabelan bahan kimia yang dapat menghambat kelancaran arus perdagangan maupun pengamanan bahan kimia. Diharapkan dalam penerapan sistem harmonisasi global tentang klasifikasi dan pelabelan bahan kimia dapat mencegah terjadinya kecelakaan kerja akibat bahan kimia berbahaya yang disebabkan kontak langsung dengan bahan kimia serta memfasilitasi perdagangan internasional bahan kimia dimana bahaya bahan kimia tersebut sudah dikaji dan diidentifikasi dengan basis internasional.

\section{METODE}

Penelitian ini apabila ditinjau dari aspek tujuan dan sifatnya termasuk rancang bangun observasional karena tidak dilakukan perlakuan pada subjek penelitian. Penelitian bersifat deskriptif, subjek yaitu pekerja yang bekerja di unit urea dan akan dilakukan pengukuran variabel. Berdasarkan waktunya, penelitian termasuk cross sectional karena dilakukan dalam satu periode waktu tertentu.

Lokasi penelitian dilakukan di PT Petrokimia Gresik yang terletak di Jalan Jendral Ahmad Yani, Gresik, Jawa Timur. Waktu pengambilan data penelitian dilaksanakan pada 6 April sampai dengan 30 April 2015. Variabel yang diteliti yaitu penerapan sistem harmonisasi global, kalsifikasi bahaya, penyediaan dan pemasangan SDS atau LDK, dan penyediaan dan pemasangan label.

Pengumpulan data primer dilakukan dengan observasi langsung dan melalui checklist. Data pendukung yaitu data sekunder diperoleh dari dokumen perusahaan meliputi profil perusahaan, proses produksi Urea, kebijakan K3, dan lainnya.

Data yang telah diperoleh selanjutnya akan dideskripsikan dalam bentuk narasi dan tabel, kemudian akan disesuaikan dengan peraturan maupun teori yang sudah ada mengenai Sistem Harmonisasi Global.

\section{HASIL}

\section{Gambaran Umum PT Petrokimia Gresik}

PT Petrokimia Gresik bergerak di bidang produksi pupuk, bahan-bahan kimia dan jasa lainnya seperti konstruksi dan engineering. PT Petrokimia Gresik merupakan Badan Usaha Milik Negara
(BUMN) dalam lingkup Departemen Perindustrian dan Perdagangan RI. Sesuai dengan SK Kementerian Hukum \& HAM Republik Indonesia, Nomor: AHU-17695.AH.01.02 Tahun 2012 PT. Petrokimia Gresik bernaung dibawah Holding Company PT Pupuk Indonesia (Persero). PT. Petrokimia Gresik merupakan produsen pupuk terlengkap di Indonesia yang memproduksi berbagai macam pupuk, seperti: Urea, ZA, SP-36, ZK, NPK, Phonska, NPK Kebomas, dan pupuk organik petroganik. PT. Petrokimia Gresik juga memproduksi produk non pupuk, antara lain Asam Sulfat, Asam Fosfat, Urea, Dry Ice, Aluminum Fluoride, Cemen Retarder, dll. PT. Petrokimia Gresik memiliki kapasitas produksi pupuk sebesar 4.310 .000 ton/tahun dan kapasitas produksi non pupuk sebesar 1.777 .600 ton/tahun. Dengan kapasitas produksi yang sedemikian besar, keberadaan PT. Petrokimia Gresik sangat mendukung program pemerintah dalam rangka meningkatkan produksi pertanian dan ketahanan pangan nasional

PT Petrokimia Gresik dalam meningkatkan hasil produksinya memberikan jaminan kepada para pekerja dengan meningkatkan keselamatan dan kesehatan kerja para pekerjanya. PT Petrokimia Gresik memberikan berbagai program keselamatan dan kesehatan kerja untuk menciptakan kerja yang aman dan nyaman, salah satu program yang diterapkan oleh PT Petrokimia Gresik adalah program Globally Harmonized System/Sistem Harmonisasi Global. Program GHS merupakan program yang berkonsentrasi pada penanganan bahan kimia berbahaya yang sudah menjadi standar internasional dalam hal perdagangan import-export.

PT Petrokimia Gresik berlokasi di Jalan Jenderal Ahmad Yani Gresik dan juga memiliki kantor perwakilan Jakarta yang beralamat di jalan Tanah Abang III No. 16 Jakarta Pusat. PT Petrokimia Gresik menempati lahan seluas 450 hektar berlokasi di Kabupaten Gresik, Propinsi Jawa Timur.

PT Petrokimia Gresik memiliki visi, misi dan budaya perusahaan. Visi PT Petrikimia Gresik adalah menjadi produsen pupuk dan produk kimia lainya yang berdaya saing tinggi dan produknya paling diminati konsumen. Misi PT Petrokimia Gresik adalah mendukung penyediaan pupuk nasional untuk tercapainya program swasembada pangan, meningkatkan hasil usaha untuk menunjang kelancaran kegiatan operasional dan pengembangan usaha perusahaan, dan mengembangkan potensi 
usaha untuk mendukung industry kimia nasional dan berperan aktif dalam community development.

Budaya perusahaan PT Petrokimia Gresik antara lain adalah mengutamakan keselamatan dan kesehatan kerja serta pelestarian lingkungan hidup dalam setiap kegiatan operasional, memanfaatkan profesionalisme untuk peningkatan kepuasan pelanggan, meningkatkan inovasi untuk memenangkan bisnis, mengutamakan integritas di atas segala hal, serta berupaya membangun semangat kelompok yang sinergistik.

PT Petrokimia Gresik bertekad menjadi produsen pupuk dan produk kimia lainnya yang berdaya saing tinggi dan produknya diminati oleh konsumen. Penyediaan produk pupuk, produk kimia dan jasa yang berkualitas sesuai permintaan pelanggan dilakukan melalui proses produksi dengan menerapkan sistem manajemen yang menjamin mutu, pencegahan pencemaran dan berbudaya Keselamatan dan Kesehatan Kerja (K3) serta penyempurnaan secara bertahap dan berkesinambungan. Untuk mendukung tekad tersebut, manajemen berupaya memenuhi standar mutu yang ditetapkan, peraturan lingkungan, ketentuan dan norma $\mathrm{K} 3$ serta peraturan perundangan terkait lainnya. Seluruh karyawan bertanggung jawab dan mengambil peran dalam upaya meningkatkan keterampilan untuk pengembangan produk dan jasa yang berkualitas, penaatan terhadap peraturan lingkungan dan ketentuan K3 serta menjunjung tinggi integritas.

\section{Gambaran Umum Unit Urea PT Petrokimia Gresik}

Jumlah karyawan unit Urea PT Petrokimia Gresik berdasarkan data yang diperoleh dari Kepala Seksi (Kasi) unit Urea pada bulan April 2015 berjumlah sebanyak 32 orang. Pekerja pada unit urea memiliki beberapa pembagian yang dilakukan

Tabel 1. Jumlah Pekerja pada Unit Urea Tahun 2015

\begin{tabular}{cc}
\hline Pekerja & Jumlah (orang) \\
\hline Regu A & 8 \\
Regu B & 8 \\
Regu C & 8 \\
Regu D & 8 \\
Normal Day & 4 \\
\hline Total & $\mathbf{3 6}$ \\
\hline
\end{tabular}

di unit urea dengan pembagian regu dan normal day yang dijelaskan pada tabel 1 .

Proses produksi urea bersifat berkelanjutan dengan kapasitas 1400 ton/hari. Pabrik menggunakan gas $\mathrm{CO}_{2}$ dan amoniak cair dari pabrik urea sebagai bahan baku. Gas $\mathrm{CO}_{2}$ dan amoniak cair direaksikan membentuk amonium karbamat $\left(\mathrm{NH}_{2} \mathrm{COONH}_{4}\right)$ dan dilanjutkan dehidrasi karbamat membentuk urea $\left(\mathrm{NH}_{2} \mathrm{CONH}_{2}\right)$. Larutan urea dimurnikan dengan cara menguraikan dan memisahkan ammonium karbamat yang tidak terkonversi dengan penurunan tekanan dan pemanasan dalam dua tingkat decomposer. Larutan urea selanjutnya akan dipekatkan dengan cara menguapkan air dan larutan lainnya. Hal tersebut dilakukan hingga kepekatan 99,7\% berat. Larutan urea pekat diproses menjadi butiran dengan cara di spray dan pendinginan menggunakan udara. $\mathrm{Gas}_{3}$ dan $\mathrm{CO}_{2}$ yang terpisahkan diambil kembali dalam dua tingkat absorbsi menggunakan proses kondensat sebagai absorben dan kemudian dikembalikan ke tahap sintesis.

Uap air yang teruapkan dan terpisahkan didinginkan dan dikondensasikan. Sejumlah kecil urea, $\mathrm{NH}_{3}$ dan $\mathrm{CO}_{2}$ dalam kondensat diolah dan dipisahkan dengan cara stripping dan hidrolisasi kemudian dikirim kembali untuk direaksikan membentuk urea.

Tabel 2. Bahan-Bahan dalam Proses Produksi pada Unit Urea Tahun 2015

\begin{tabular}{ll}
\hline Bahan baku & \multicolumn{1}{c}{ Fungsi } \\
\hline Amonia Cair & $\begin{array}{l}\text { Bahan baku utama dalam pembuatan } \\
\text { Urea pada unit Urea }\end{array}$ \\
$\begin{array}{l}\text { Gas Karbon } \\
\text { Dioksida }\end{array}$ & $\begin{array}{l}\text { Untuk menekan amonia cair agar } \\
\text { menjadi karbamat, nanti karbamat } \\
\text { akan menjadi butiran-butiran kecil }\end{array}$ \\
Asam Sulfat & Regenerasi kation exchanger \\
Natrium & Regenerasi anion exchanger \\
Hidroksida & Soda) \\
Anti caking & Agar produk urea tidak menggumpal \\
Pewarna urea & Untuk mewarnai urea subsidi \\
Kation & $\begin{array}{l}\text { Untuk menangkap ion positif pada } \\
\text { filtered water }\end{array}$ \\
Anion & $\begin{array}{l}\text { Untuk menangkap ion negatif pada } \\
\text { filtered water }\end{array}$ \\
Asam nitrat & Digunakan saat cleaning line pipa \\
\hline
\end{tabular}




\section{Penerapan Komunikasi Bahaya melalui Globally Harmonized System}

Globally Harmonized System (GHS) diterapkan oleh PT Petrokimia Gresik pada tahun 2009 sesuai dengan diterbitkannya Peraturan Menteri Perindustrian Republik Indonesia nomor: 87/ M-IND/PER/9/2009 tentang Sistem Harmonisasi Global Klasifikasi dan Label pada Bahan Kimia dan ditambahkan dengan Peraturan Jendral Industri Agro dan Kimia nomor: 21/IAK/PER/4/2010 tentang Petunjuk Teknis Penerapan Sistem Harmonisasi Global Klasifikasi dan Label Pada Bahan Kimia.

Pada tahun 2013 terdapat perubahan peraturan oleh Menteri Perindustrian yaitu Peraturan Menteri Perindustrian nomor: 23/M-IND/PER/4/2013 tentang Perubahan atas Peraturan Menteri Perindustrian Nomor: 87/M-IND/PER/9/2009 tentang Sistem Harmonisasi Global Klasifikasi dan Label pada Bahan Kimia.

Pada tahun 2013 terdapat perubahan peraturan oleh Menteri Perindustrian yaitu Peraturan Menteri Perindustrian nomor: 23/M-IND/PER/4/2013 tentang Perubahan atas Peraturan Menteri Perindustrian Nomor: 87/M-IND/PER/9/2009 tentang Sistem Harmonisasi Global Klasifikasi dan Label pada Bahan Kimia. Pada peraturan petunjuk teknis penerapan Sistem Harmonisasi Global juga terdapat perubahan yaitu dari Peraturan Jendral Industri Agro dan Kimia nomor: 21/IAK/PER/4/2010 tentang Petunjuk Teknis Penerapan Sistem Harmonisasi Global Klasifikasi dan Label Pada Bahan Kimia diubah dengan Peraturan Jenderal Basis Industri Manufaktur nomor: 04/BIM/PER/1/2014 Tentang Petunjuk Teknis dan Petunjuk Pengawasan Pelaksanaan Sistem Harmonisasi Global Klasifikasi dan Label pada Bahan Kimia, dengan diubahnya peraturan tersebut pihak PT Petrokimia Gresik sendiri sudah mengubah peraturan yang digunakan dengan peraturan yang terbaru.

Tabel 3. Penerapan Komunikasi Bahaya melalui SGS pada unit Urea Tahun 2015

\begin{tabular}{llc}
\hline \multicolumn{1}{c}{ Penerapan SGS } & Kesesuaian & Nilai \\
\hline $\begin{array}{l}\text { Klasifikasi bahaya } \\
\begin{array}{l}\text { Penyediaan dan pemasangan } \\
\text { LDK }\end{array}\end{array}$ & Sesuai & $33 \%$ \\
$\begin{array}{l}\text { Penyediaan dan pemasangan sesuai } \\
\text { label }\end{array}$ & - \\
\hline Total & Sesuai & $33 \%$ \\
\hline
\end{tabular}

Penerapan komunikasi bahaya melalui Globally Harmonized System PT Petrokimia Gresik memiliki tiga point penting, yaitu klasifikasi bahaya bahan kimia, penyediaan dan pemasangan LDK dan penyediaan label dan pemasangan label. Tiga hal tersebut adalah inti dari penerapan komunikasi bahaya melalui Sistem Harmonisasi Global untuk melakukan pencegahan terhadap kecelakaan akibat bahan kimia. Tabel 3 merupakan tabel hasil penelitian tentang penerapan komunikasi bahaya melalui GHS.

Klasifikasi bahaya yang dilakukan sesuai dengan format yang sudah ditentukan oleh peraturan yang berlaku dan seluruh bahan kimia memiliki LDK, tetapi untuk penempatan dan format diketahui tidak sesuai serta untuk penyediaan label sudah dilakukan tetapi kurang dalam hal pemeliharaan

Untuk menunjang terciptanya GHS pada PT Petrokimia Gresik, PT Petrokimia Gresik memberikan beberapa tambahan sendiri, tambahan tersebut adalah pelatihan GHS kepada Safety Representative yang ada di area kerja setahun sekali, Buku saku K3 yang isinya terdapat penerapan Sistem Harmonisasi Global, pelaporan yang dilakukan oleh PT Petrokimia Gresik langsung ditangani oleh Menteri Perindustrian karena PT Petrokimia merupakan perusahaan yang ditunjuk oleh Menteri Perindustrian sebagai acuan dalam menerapkan GHS di perusahaan lain, Dilakukan inspeksi pengadaan dan pendistribusian rambu dan blower yang dilakukan oleh Inspector serta dibantu oleh Safety Officer kantor pusat LK3 yang setiap minggu sekali, papan informasi yang berisikan info tentang bahan kimia dan bahaya yang bisa ditimbulkan, pelatihan penanganan bahan kimia yang dilakukan minimal 1 tahun sekali, memberikan transportation card yang berisikan informasi tentang bahan kimia yang diangkut, safety induction untuk pengemudi B3, dan brosur pedoman penanganan B3.

\section{Klasifikasi Bahaya Bahan Kimia}

Penerapan klasifikasi bahaya bahan kimia dilakukan untuk menentukan tingkat bahaya bahan kimia tersebut. Berdasarkan hasil wawancara, klasifikasi pada bahaya bahan kimia belum dilakukan secara menyeluruh terhadap semua bahan kimia yang ada di PT Petrokimia Gresik. Bahan kimia tunggal merupakan prioritas utama untuk dilakukan klasifikasi dan untuk bahan campuran PT Petrokimia Gresik juga dilakukan klasifikasi yang sama. sehingga dalam proses klasifikasi bahan kimia semua dapat diklasifikasikan. 
Klasifikasi bahaya bahan kimia yang dilakukan oleh PT Petrokimia Gresik sudah sesuai dengan format kategori/divisi/tipe pada Peraturan Menteri Perindustrian nomor: 23/M-IND/PER/4/2013 yang dijelaskan pada pasal 4 bahwa klasifikasi berdasarkan kriteria bahaya yang terdiri dari 16 bahaya fisik, 10 bahaya terhadap kesehatan, dan 3 bahaya terhadap lingkungan. PT Petrokimia Gresik dalam melakukan klasifikasi menggunakan metode logika pengambilan keputusan/decision Logic.

\section{Penyediaan dan Pemasangan LDK}

Hasil observasi menunjukkan bahwa semua bahan kimia yang ada pada unit Urea PT Petrokimia Gresik telah tersedia SDS/LDK yang diletakkan di ruang Display Control System dan ruang kepala bagian unit urea yang cukup jauh jaraknya dari area kerja. Terdapat dua macam SDS/LDK yang digunakan oleh PT Petrokimia Gresik yaitu LDK/ SDS yang dikeluarkan oleh PT Petrokimia sendiri. PT Petrokimia sendiri memiliki dua macam SDS/ LDK, yaitu SDS/LDK yang sesuai dengan Peraturan Menteri Perindustrian no. 23/M-IND/PER/4/2013 dan SDS/LDK yang diterbitkan pada tahun 199 dan LDK/SDS dari pemasok. SDS/LDK dari pemasok menggunakan bahasa asing sehingga sulit dipahami oleh pekerja.

SDS/LDK yang memiliki format yang sesuai dengan peraturan di atas terdapat pada kantor Pusat Lingkungan Kesehatan dan Keselamatan Kerja. Namun tidak disebarkan ke lapangan, sehingga SDS/LDK yang digunakan adalah SDS/LDK yang dibuat pada tahun 1998 dan hanya memiliki 11 section. SDS/LDK dari pemasok yang rata-rata menggunakan bahasa asing sesuai dengan dari mana bahan tersebut diperoleh. PT Petrokimia Gresik melakukan pengkajian ulang terhadap SDS/LDK setiap 5 tahun sekali.

Sebagian besar SDS/LDK yang digunakan tidak sesuai dengan format yang sudah ditentukan

Tabel 4. Hasil Checklist Klasifikasi Bahaya Bahan Kimia pada unit Urea Tahun 2015

\begin{tabular}{lcc}
\hline Ketentuan & Y & T \\
\hline Tersedia & $\checkmark$ & \\
Bahaya fisik & $\checkmark$ & \\
Bahaya kesehatan & $\checkmark$ & \\
Bahaya lingkungan & $\checkmark$ & \\
27 jumlah bahaya fisik, & $\checkmark$ & \\
kesehatan, dan lingkungan & & \\
\hline
\end{tabular}

Tabel 5. Penyediaan dan Pemasangan SDS/LDK Bahan Kimia pada unit Urea Tahun 2015

\begin{tabular}{lccc}
\hline $\begin{array}{c}\text { Nama Bahan } \\
\text { Kimia }\end{array}$ & $\begin{array}{c}\text { Tersedia } \\
\text { SDS }\end{array}$ & $\begin{array}{c}\text { Sesuai dengan } \\
\text { PERMENPERIND } \\
\text { No. 23/M-IND/ } \\
\text { PER/4/2013 }\end{array}$ \\
\cline { 2 - 4 } Y & \multicolumn{2}{c}{ T } & T \\
\hline PT Petrokimia Gresik & $\checkmark$ & \\
Urea & $\checkmark$ & & $\checkmark$ \\
Amonia Cair & $\checkmark$ & & $\checkmark$ \\
Gas Karbon & $\checkmark$ & & $\checkmark$ \\
Dioksida & & & $\checkmark$ \\
Asam Sulfat & $\checkmark$ & & \\
Natrium & $\checkmark$ & & $\checkmark$ \\
Hidroksida & & $\checkmark$ & \\
Pemasok & & $\checkmark$ & \\
Anti caking & $\checkmark$ & & $\checkmark$ \\
Kation & $\checkmark$ & & \\
Anion & $\checkmark$ & & \\
Asam nitrat & $\checkmark$ & &
\end{tabular}

oleh peraturan yang berlaku. SDS/LDk yang tidak sesuai dengan format adalah SDS/LDK bahan kimia yang dikeluarkan oleh PT Petokimia Gresik sendiri, sedangkan untuk SDS/LDK dari pemasok sebagian besar menggunakan bahasa asing sehingga susah untuk dipahami oleh pekerja.

\section{Penyediaan dan Pemasangan Label}

Pelabelan pada Sistem Harmonisasi Global tentang Klasifikasi dan Pelabelan Bahan Kimia terdiri dari dua hal, yaitu simbol/piktogram dan label. Berdasarkan hasil observasi, terdapat dua jenis pelabelan, yaitu yang dibuat oleh PT Petrokimia dan yang sudah terdapat pada kemasan produk dari pemasok. Label yang dikeluarkan oleh PT Petrokimia Gresik hanyalah label pada bahan Kimia Amonia dan Asam Sulfat karena hanya bahan tersebut yang dihasilkan oleh PT Petrokimia Gresik sendiri, sedangkan untuk Bahan Kimia lainnya adalah dari pemasok.

Di lapangan terdapat tangki amonia reservisor, tangki penyimpanan asam sulfat, dan tangki penyimpanan natrium hidroksida yang tidak diberikan label, tetapi label bahan-bahan tersebut sudah tersedia dalam gudang kantor pusat LK3. PT Petrokimia Gresik memiliki hal positif dalam hal pelabelan, dimana selalu tersedia papan informasi 
Tabel 6. Penyediaan dan Pemasangan Label Bahan Kimia pada Unit Urea Tahun 2015

\begin{tabular}{|c|c|c|c|c|}
\hline \multirow[t]{2}{*}{$\begin{array}{l}\text { Nama } \\
\text { Bahan } \\
\text { Kimia }\end{array}$} & \multicolumn{2}{|c|}{$\begin{array}{c}\text { Tersedia } \\
\text { Label }\end{array}$} & \multicolumn{2}{|c|}{$\begin{array}{c}\text { Sesuai dengan } \\
\text { PERMENPERIND } \\
\text { nomor: 23/M-IND } \\
\text { PER/4/2013 }\end{array}$} \\
\hline & $\mathbf{Y}$ & $\mathbf{T}$ & $\mathbf{Y}$ & $T$ \\
\hline Urea & $\checkmark$ & & $\checkmark$ & \\
\hline Amonia Cair & $\checkmark$ & & $\checkmark$ & \\
\hline $\begin{array}{l}\text { Gas Karbon } \\
\text { Dioksida }\end{array}$ & $\checkmark$ & & $\checkmark$ & \\
\hline Asam Sulfat & $\checkmark$ & & $\checkmark$ & \\
\hline $\begin{array}{l}\text { Natrium } \\
\text { Hidroksida }\end{array}$ & $\checkmark$ & & $\checkmark$ & \\
\hline Anti caking & $\checkmark$ & & $\checkmark$ & \\
\hline Kation & $\checkmark$ & & $\checkmark$ & \\
\hline Anion & $\checkmark$ & & $\checkmark$ & \\
\hline Asam nitrat & $\checkmark$ & & $\checkmark$ & \\
\hline
\end{tabular}

yang isi dalam papan informasi tersebut adalah sebagian kecil isi pelabelan menurut Peraturan Menteri Perindustrian no. 23/M-IND/PER/4/2013. Kajian ulang Pelabelan dilakukan oleh PT Petrokimia Gresik setiap 5 tahun sekali, seperti yang diatur dalam peraturan yang berlaku. Tabel hasil observasi penyediaan dan pemasangan label pada bahan kimia di unit urea PT Petrokimia Gresik terdapat pada tabel 6 .

Pemeliharaan label merupakan masalah dalam hal pelabelan, karena terdapat beberapa tangki bahan kimia yang tidak ditempeli oleh label atau pictogram. Persediaan pada gudang masih banyak tersedia. Hal tersebut menunjukkan apabila pemeliharaan masih kurang dan merupakan masalah yang harus diselesaikan.

\section{PEMBAHASAN}

\section{Penerapan Komunikasi Bahaya melalui Globally Harmonized System}

Penerapan komunikasi bahaya melalui GHS di PT Petrokimia Gresik secara keseluruhan hasil dari penerapan komunikasi bahaya melalui termasuk dalam kategori cukup sehingga terdapat variabel yang hasil nilainya tidak memenuhi standar penerapan GHS. Terdapat 2 (dua) variabel penelitian $(66 \%)$ yang diterapkan sesuai dengan Peraturan Menteri Perindustrian nomor: 23/MIND/PER/4/2013 dan Peraturan Jenderal Basis
Industri Manufaktur nomor: 04/BIM/PER/1/2014 yaitu variabel klasifikasi pada bahan kimia dan pemasangan label, sehingga terdapat satu variabel yang tidak memenuhi nilai standar yang dibutuhkan, yaitu pada variabel penyediaan dan pemasangan LDK/SDS.

Penerapan komunikasi bahaya melalui GHS di PT Petrokimia Gresik memiliki kekurangan dalam menerapkan metode tersebut, sehingga pihak perusahaan dan pemerintah seharusnya melakukan suatu program dalam mendampingi dan membantu suatu perusahaan untuk menerapkan metode tersebut sebagai salah satu syarat wajib berdirinya perusahaan khususnya perusahaan dalam bidang pengelolaan bahan berbahaya dan beracun (B3).

\section{Klasifikasi Bahaya}

Klasifikasi bahaya merupakan salah satu metode dalam melakukan perlakuan terhadap bahan kimia dalam menerapkan GHS di perusahaan. PT Petrokimia Gresik dalam melakukan klasifikasi belum secara menyeluruh terhadap bahan kimia tunggal yang terdapat pada proses produksi maupun hasil produksi, tetapi dalam Peraturan Menteri Perindustrian nomor: 23/M-IND/PER/4/2013 tentang Perubahan Atas Peraturan Menteri Perindustrian Nomor: 87/M-IND/PER/9/2009 tentang Sistem Harmonisasi Global Klasifikasi dan Label pada Bahan Kimia dan Peraturan Jenderal Basis Industri Manufaktur nomor: 04/BIM/PER/1/2014 Tentang Petunjuk Teknis dan Petunjuk Pengawasan Pelaksanaan Sistem Harmonisasi Global Klasifikasi dan Label pada Bahan Kimia menjelaskan pada pasal 4 setiap bahan kimia tunggal hasil produksi dalam negeri maupun importir harus dilakukan klasifikasi. Pada pasal 4 tersebut, setiap menjelaskan bahwa seluruh bahan kimia pada suatu perusahaan industri harus dilakukan klasifikasi dan untuk bahan kimia campuran adalah bersifat sukarela. Klasifikasi bahaya bahan kimia sejarah menyeluruh harus dilakukan oleh PT Petrokimia Gresik karena hal tersebut sudah dijelaskan pada peraturan di atas.

\section{Penyediaan dan Pemasangan SDS/LDK}

SDS/LDK merupakan dokumen/ lembar data yang menjelaskan tentang karakteristik, komposisi, bahaya fisik, dan kesehatan suatu bahan kimia. Lembar data ini juga menjelaskan tentang cara penanganan dan penyimpanan bahan kimia yang aman dan sesuai dengan prosedur yang ditentukan pada pemadaman kebakaran. Menurut 
Tabel 7. List Isi SDS/LDK pada Unit Urea Tahun 2015

\begin{tabular}{lcc}
\hline \multicolumn{1}{c}{ Isi SDS } & Ada & $\begin{array}{c}\text { Tidak } \\
\text { ada }\end{array}$ \\
\hline $\begin{array}{l}\text { Identifikasi senyawa (tunggal atau } \\
\text { campuran) }\end{array}$ & $\checkmark$ & \\
Identifikasi bahaya & $\checkmark$ & \\
Komposisi atau informasi tentang \\
bahan penyusun senyawa tunggal & & \\
Tindakan PPPK & $\checkmark$ & \\
Tindakan pemadaman kebakaran & $\checkmark$ & \\
Tindakan penanggulangan & $\checkmark$ & \\
kebakaran & & \\
Penanganan dan penyimpanan & $\checkmark$ & \\
Kontrol paparan atau perlindungan & $\checkmark$ & \\
diri & & \\
Sifat fisik dan kimia & $\checkmark$ & \\
Stabilitas dan reaktivitas & $\checkmark$ & \\
Informasi toksikologi & $\checkmark$ & \\
Informasi ekologi & $\checkmark$ & \\
Pembuangan limbah & & $\checkmark$ \\
Pertimbangan pembuangan atau & & $\checkmark$ \\
pemusnahan & & \\
Informasi yang berkaitan dengan & & $\checkmark$ \\
regulasi & & \\
Informasi lain & $\checkmark$ & \\
\hline
\end{tabular}

Siswanto (1991). SDS/LDK hendaknya disimpan di suatu tempat yang dekat dengan tempat kerja karyawan dan selalu tersedia pada setiap shift. SDS/ LDK yang berada pada ruang Display Control System seharusnya ditempatkan pada area kerja dan diberikan tempat khusus agar awet sehingga dapat dimanfaatkan dan difungsikan oleh pekerja apabila terjadi kondisi yang tidak diinginkan, tidak disimpan di ruang Display Control System yang hanya berfungsi sebagai dokumentasi dan tidak dapat dimanfaatkan oleh pekerja.

Berdasarkan Peraturan Menteri Perindustrian nomor: 23/M-IND/PER/4/2013 tentang Perubahan Atas Peraturan Menteri Perindustrian Nomor: 87/ M-IND/PER/9/2009 tentang Sistem Harmonisasi Global Klasifikasi dan Label pada Bahan Kimia dan Peraturan Jenderal Basis Industri Manufaktur nomor: 04/BIM/PER/1/2014 tentang Petunjuk Teknis dan Petunjuk Pengawasan Pelaksanaan Sistem Harmonisasi Global Klasifikasi dan Label pada Bahan Kimia. Pasal 9 menjelaskan bahwa terdapat 16 Section yang harus tercantum dalam SDS/LDK secara teratur dan sesuai format yang telah ditentukan di peraturan sehingga seharusnya memerlukan upaya tindak lanjut dalam pemenuhannya.

Tabel 7 dapat menjelaskan bahwa apabila SDS/ LDK yang terdapat pada unit urea terdapat beberapa kekurangan dalam isi SDS/LDK tersebut. SDS/ LDK yang dikeluarkan oleh pemasok sebagian menggunakan bahasa asing akan tetapi pada pasal 10 SDS/LDK wajib menggunakan bahasa Indonesia dan dapat juga disertai dengan bahasa internasional yang digunakan sebagai bahasa resmi sehingga SDS/ LDK dapat dengan mudah dibaca dan dipahami oleh pekerja dalam memanfaatkannya saat terjadi kondisi darurat atau semacamnya.

\section{Penyediaan dan Pemasangan Label}

Pelabelan pada bahan kimia berbahaya merupakan hal yang harus dilakukan sebagai informasi penting dalam pengelolaannya. Pelabelan pada pasal 5 Peraturan Menteri Perindustrian nomor: 23/M-IND/PER/4/2013 dan pasal 5 dalam Peraturan Jenderal Basis Industri Manufaktur nomor: 04/BIM/ $\mathrm{PER} / 1 / 2014$ bahwa label wajib terdapat identitas bahan kimia, piktogram bahaya, kata sinyal, pernyataan bahaya, pernyataan kehati-hatian, dan identitas produsen dan/atau pemasok atau importir. Peraturan tersebut sudah terlaksana dengan baik akan tetapi hanya sedikit kekurangan, yaitu inspeksi label dan dalam menjaga kondisi label agar dapat dengan mudah di baca, jelas terlihat, tidak mudah rusak, tidak mudah lepas dalam kemasan, dan tidak mudah pudar karena pengaruh sinar matahari, udara, air atau lainnya seperti yang dijelaskan pada pasal 5 Peraturan Menteri Perindustrian nomor: 23/M-IND/ PER/4/2013. Hasil observasi di tempat penelitian, kondisi label pada bahan kimia banyak yang sudah tidak bisa terbaca dengan jelas, seperti label pada bahan kimia dalam kemasan yaitu asam nitrat yang digunakan untuk melakukan Cleaning. Bahan kimia yang tidak memiliki label akan berdampak langsung pada pekerja yang akan melakukan pekerjaan, hal tersebut dapat meningkatkan angka penyakit akibat kerja dan kecelakaan yang disebabkan bahan kimia tersebut. Untuk mencegah hal tersebut perlu dilakukan inspeksi pada lapangan dalam hal pelabelan bahan kimia, di dalamnya berisikan pemasangan label, keadaan label, pemasangan piktogram, dan keadaan piktogram. 


\section{SIMPULAN}

Penerapan Globally Hamonized System pada PT Petrokimia Gresik di unit urea dalam kategori cukup dengan nilai $66 \%$ atau terdapat satu variabel yang tidak sesuai dengan penerapan. Klasifikasi dan pelabelan sudah sesuai dengan peraturan perundangan dan sebagian besar perlu adanya perbaikan pada klasifikasi dan pelabelan. Terdapat dua macam SDS/LDK, yaitu SDS/LDK yang lama (11 section) dan SDS/LDK dari pemasok yang sebagian menggunakan bahasa asing sedangkan untuk pemasangan SDS/LDK jauh dari tempat/area kerja sehingga pekerja tidak dapat memanfaatkan SDS/LDK apabila terjadi kecelakaan kerja. Berkurangnya $60 \%$ angka kecelakaan akibat bahan kimia dan berkurangnya $85 \%$ korban kecelakaan akibat bahan kimia dari tahun 2004 ke 2015 . Penerapan Globally Harmonized System/Sistem Harmonisasi Global di PT Petrokimia Gresik adalah salah satu faktor yang dapat menurunkan level kecelakaan akibat bahan kimia pada perusahaan tersebut.

\section{DAFTAR PUSTAKA}

Damanik, L. H., Adi H. H., Totok G., \& Pramono H., 2015. Model Pengendalian Kesehatan Tenaga Kerja pada Kegiatan Pengecoran Logam Tradisional Studi Kasus di Kawasan Industry Batur Klaten-Jawa Tengah. Jurnal Teknosains. [e-Jurnal] 4(2): pp. 155-171

Lesmana, D. S., 2007. MSDS dan Implementasinya Berdasarkan GHS. Seminar Nasional K3. Bogor: Chemwatch/Chemcare Asia
Mansyur, M., 2007. Manajemen Risiko Kesehatan di Tempat Kerja. Majalah Kedokteran Indonesia (MKI), 57 (9): pp. 285-288

Peraturan Menteri Perindustrian Republik Indonesia Nomor: 87/M-IND/PER/9/2009 tentang Sistem Harmonisasi Global Klasifikasi dan Label pada Bahan Kimia. Jakarta: Departemen Perindustrian

Peraturan Direktur Jendral Basis Industri Manufaktur Nomor 04/BIM/PER/1/2014 tentang Petunjuk Teknis dan Petunjuk Pengawasan Pelaksanaan Sistem Harmonisasi Global Klasifikasi dan Label Pada Bahan Kimia. Jakarta: Departemen Perindustrian

Peraturan Jendral Industri Agro dan Kimia Nomor: 21/IAK/PER/4/2010 tentang Petunjuk Teknis Penerapan Sistem Harmonisasi Global Klasifikasi dan Label Pada Bahan Kimia. Jakarta: Departemen Perindustrian

Peraturan Menteri Perindustrian Republik Indonesia Nomor 23/M-IND/PER/4/2013 tentang Perubahan Atas Peraturan Menteri Perindustrian. Nomor 87/ M-IND/PER/9/2009 tentang Sistem Harmonisasi Global Klasifikasi dan Label Pada Bahan Kimia. Jakarta: Departemen Perindustrian

Siswanto, A., 1991. Bahaya Bahan Kimia. Handout. Surabaya: Bagian Toksikologi Industri Universitas Airlangga

Harjanto, N. T., Suliyanto, Endang Sukesi I., 2011. Manajemen Bahan Kimia Berbahaya dan Beracun Sebagai Upaya Keselamatan dan Kesehatan Kerja serta Perlindungan Lingkungan. Jurnal Ilmiah Pengelolaan Instalasi Nuklir (PIN), [e-Jurnal] 8 (IV): pp. 54-67 